Journal Plus Education, ISSN: 1842-077X, E-ISSN (online) 2068-1151 Vol XIX (2018), No. 1. pp. 131-143

\title{
SELF-VALUING, ATTITUDE TOWARD SELF AND TOWARD LIFE OF PEOPLE WITH MOTOR DISABILITIES
}

\author{
Lupu DACIANA, Ph.D., \\ Transilvania University of Brasov \\ dacianalupu@unitbv.ro
}

\begin{abstract}
The actual research has pursued the investigation of the attitude toward the self and the attitude toward life of the women and men with motor disabilities and also analised the self-valuing of people with motor disabilities depending on the nature of the disability (innate or acquired) and the level of education ( $N$ - 93 subjects). Women more than men, feel that the presence of disability is affecting their attitude toward the self and toward life. Comparing the results for self-valuing, depending on the nature of the disability - innate or acquired, we found a breakdown of the results in favor of innate disabilities. People with innate motor disability are self-valuing better than those who have acquired disability during the life.
\end{abstract}

Key words: motor disability; attitude toward the self; attitude toward life; self-valuing; gender perspective; nature of the disability (innate or acquired);

\section{Introduction}

The ability to walk is one of the attributes of human independence and autonomy. So we talk about: walking with a continuous step, walking with symmetry step, deviation (of path and turning). Coarse and fine motor skills are an essential component of many daily activities such as clothingstripping, feeding or playing/working. Poor fine motor skills may lead to difficulties in doing academic activities, increasing anxiety and low selfesteem (Gaul, Issartel, 2016), a negative self-image (David, 2015), depression (Dauvergne, et. al., 2007). Adolescents with low motor skills have diminished their perception of physical self and consequently tend to avoid physical activities (McIntyre et al., 2015). The etiology of motor disabilities calls for perinatal etiologies: hypoxia at birth $(6.3 \%)$; postnatal etiology: neonatal infections such as meningitis and hyperthermia of unknown origin $(9.7 \%)$, seizures $(4.2 \%)$ and jaundice $(2.8 \%)$; prenatal (2.8\%), multiple pregnancies (2.1\%) (Batoui, Habbari, Hassnaoui, Ezoubair, $2015)$, prenatal etiologies dominated by low birth weight (16.7\%). 


\section{Background}

As members of society, it is normal to take into account the need for services and support for people with disabilities to improve their lives as well as to initiate strategies to prevent their health deterioration (McDermott, Turk, 2011). Health policies in support of people with disabilities support the importance of maintaining basic functional status and promoting health. The relationship between the promotion of health through physical activity and the prevention/ reduction of secondary conditions among people with various physical disabilities was analyzed. In this case, there was an increase in community's participation in activities for people with physical disabilities (White, Gonda, Peterson, Drum, 2011). Parental support in physical activities of children is important, especially for young children with disabilities, given the low rates of physical activity and dependence on their parents. Parents have encouraged their children to participate in sports and physical activities. Although they have not seen their children as particularly skilled, they have understood and enjoyed physical activity and sports. Parents also understood and encouraged the mutual relationships established by their children in their physical activities with their parents (Martin, Choi, 2009). Family support was driven by how its members perceive the damage they incurred. Driven by the need to protect the person with disabilities, family members try to control the emotional effects of injuries, creating a sort of "buffer" (Ogilvie, Foster, McCloughen, Curtis, 2015). Research has highlighted the importance of effective communication, the development of physiotherapist-family relationships, cooperation-based relationships, and the adoption of a family centered approach (Greenstein, Lowell, Thomas, 2016). Music has been successful as a therapeutic intervention for people with mental and physical disabilities. Motricity and coordination can be enhanced by many musical experiences (Hatampour, Zadehmohammadi, Masoumizadeh, Sedighi, 2011). School, through teachers, supports the process of identifying people with disabilities, a process that starts with a sense of failure and early exclusion in life, continues through a turning point, and should end with the sense of control of one's own life Dvir, 2015). There is a link between chronology, disability and social inequality, which is why a new way of collaborating between social factors related to health and disability is needed. Adolescents with physical disabilities participate in fewer social activities and have fewer relationships with friends. There are a number of critical areas for adolescents with physical disabilities towards which health promotion efforts should be directed: integration into congregational groups, increasing educational aspirations (Stevens et al., 1996). Achieving an online support pilot operation has provided more interaction with colleagues for them. The organization of these groups has reduced the feeling of loneliness and has increased the social acceptance and 
confidence of people with disabilities (Stewart, 2011). Some people with motor impairment may hide their disability to avoid discrimination or stigma. For some, physical limitations can not stop them from realizing dreams, for others, this may be a struggle that affects various aspects of their lives (Nkabinde, Obiakor, Offor, Smith, 2010) and can cause mental stress (Trani, Ballard, Peña, 2016). Looking at the integration of people with physical disabilities into society, we have recently noticed that they are not only more and more integrated into society, but have even made significant achievements in sport: it is now commonplace for athletes with quadriplegia to finish the marathon. Practicing a sport is a reality for people with motor disabilities, even in a wheelchair. Wheelchair tennis has great potential for social integration of people with disabilities (Stănescu, 2014). But, all are personal, individual equations. Here's the life story of Ben, which illustrates the benefits and costs of trying to compensate for disability through sport. By allocating substantial time to sport and physical activity, Ben would seem to avoid or circumvent some of the psychosocial challenges of maturity (eg, the formation of new friendships and romantic relationships). In Ben's life, sport and physical activity posed problems in his psychosocial development (Gaskin, Andersen, Morris, 2010). When it comes to the social utility of people with disabilities, designing and designing digital games, two obstacles have been described: first, involvement of the public with special needs can introduce new practical and ethical challenges, and secondly, the use of non-design experts was criticized because the participants did not have the necessary skills to create the appropriate quality games. In addition, the results show that the design exercise involves emotional vulnerabilities that need to be considered when working with the target audience, such as expert designers (Alonso-Valerdi, Salido-Ruiz, Ramirez-Mendoza, 2015). However, the involvement of people with disabilities in designing, in technology has shown results that demonstrates that the design exercise is vulnerable to both groups (and those with motor disabilities - wheelchairs and those without motor disabilities). The risk of practical and emotional vulnerability must be taken into account when working with expert designers (Gerling, 2016). Persons with chronic physical disabilities are less satisfied with their lives than people with no health problems (van Campen, Cardol, 2009). Life satisfaction is conditioned by: civil status, general health and social well-being (Tate, Riley, Perna, Roller, 1997). Among the different types of disability, loss of motor skills is particularly serious for the consequences and sufferings produced, both physical and mental. This leads to particularly difficult and lengthy disability issues. For these people, robotics assisted for motor deficiencies can be an important alternative as it offers new possibilities for action on the environment. To adapt this problem, the technology comes in: human-computer technology (Khomiakoff, 
Czternatsy, Vandromme, 2009, Galante, Menezes, 2012; Li-Tsang, 2011) et al., 2015), 3D computer games controllers (Martins, Cunha, Morgado, 2012), keyboard and mouse, and the provision of alternative input techniques using switches (Shein, 1992). The use of robotic technology with assistive devices opens new opportunities for people with severe disabilities (tetraplegia, spinal cord injuries, and so on) both at work and in their homes. It can reduce social exclusion and support social and professional integration (Bühler, Hoelper, Hoyer, Humann, 1995). There was a lack of involvement in leisure activities, especially for people with severe disabilities. In spite of the desire to explore, the possibilities for traveling, in hiking, the possibility of access to different areas is limited to people with disabilities. The physical difficulties and high costs of accessing these areas are real obstacles to the great desire to visit the above mentioned areas (Lovelock, 2010). When there were people offering leisure time in in-door space, there was an increased commitment from people with disabilities to these activities (Wilson, Reid, Green, 2006). Participating in recreational activities is a fundamental human right and an important factor in the quality of life. It has environmental barriers (environmental factors) for children and young people with physical disabilities. Barriers have been encountered predominantly in school environments and in work environments. Significant differences were found between the rural area and the urban community (Law, Petrenchik, King, Hurley, 2007). Frequency of participation in recreational activities for children and young people with physical disabilities is associated with a variety of variables: motor capacity, cognitive ability, communication skills, age, gender (Bult et al., 2011). Children with disabilities, and especially girls, have a more limited participation in recreational activities involving social interactions (Schreuer, Sachs, Rosenblum, 2014). Adults with physical disabilities often have limited opportunities to participate in leisure activities. Virtual reality technologies can serve to expand the repertoire of recreational activities, activities accessible to people with disabilities, activities that have been perceived as pleasant and successful. They maintained a high level of interest and offered varied and motivating opportunities for time activities (Yalon-Chamovitz, Weiss (Tamar), 2008).

\section{Methodology}

\subsection{Research objectives}

The research objectives focused on: (1) analyzing attitudes towards oneself and towards the lives of people with motor disabilities; (2) analyzing the self-valuing of people with motor disabilities after the nature of disability 


\section{Research hypothesis}

The main research hypothesis was:

(1) we anticipate that self-attitude and attitude towards life are lower in women with motor disabilities than in men with motor disabilities;

(2) we anticipate that the self-valuing of motor deficiencies depends on the nature of the deficiency (innate or acquired) and by the level of education (gymnasium, lyceum, university) of the person with motor deficiencies (people with inborn impairment, respectively, those with higher education are better value-added).

\subsection{Research method}

The survey was based on the questionnaire; this is the main method used in the research. The questionnaire was built on two dimensions: leisure and attitude towards the world and life. The questionnaire was developed and validated specifically for this research (Alpha Chronbach Coefficient: 0.802.)

\subsection{Research group}

The research group comprised 93 subjects with motor disabilities (para, tetra, hemi (pleats), para, tetra, hemi, myopaths, amputated limbs). Of whom $60.2 \%$ (56 subjects) were male, the remaining 39.8\% (37 subjects) being female. Depending on origin, 73 subjects $(78.5 \%)$ from the environment urban, with the remaining 20 subjects $(21.5 \%)$ coming from rural areas. If we look at the age group, we have 14 subjects $(15.05 \%)$ aged up to 20 years; 29 subjects (31.18\%) aged $21-30$ years; 17 subjects $(18.27 \%)$ aged $31-40 ; 18$ subjects $(19.35 \%)$ aged $41-50$ years and 15 subjects $(16.12 \%)$ aged over 50 years. Another criterion for differentiation was the level of education of subjects: 16 subjects $(17.2 \%)$ who graduated gymnasium, 41 subjects (44.1\%) who graduated high school, 22 subjects $(23.7 \%)$ who graduated post-secondary school and 14 subjects (15.1\%) who graduated higher education (faculty). Engagement was another aspect of the batch characterization, so only 26 subjects $(28 \%)$ work (have a job), the remaining 67 subjects $(72 \%)$ unemployed. If we look at the subjects from the point of view of the nature of the deficiency, we have 32 subjects $(34.4 \%)$ with inborn deficiency and 61 subjects $(65.6 \%)$ who have acquired the deficiency during their lifetime.

\section{Results}

In the first hypothesis of research: we anticipate that attitude toward self and attitude toward life are lower in women with motor disabilities than in men with motor disabilities. Self-attitude and life attitudes were investigated through seven items of the questionnaire for which a median 
Alpha Chronbach Coefficient was calculated (0.579): „Am I going to get angry when I fail to do what I propose.”, ,Others are to blame for what's happening to me.”, „I was surprised to have feelings of jealousy towards people who do not experience the same deficiency.", "I'm going to cry without reason.", , I'm a person happy with my life.,", 'I'm happy.,, ,I think I'm a happy person with my life at the moment." Women are those who develop jealousy toward those who do not face the same difficulty (see Table $1): 15$ subjects - $16.13 \%$ (2.15\% rarely and $13.98 \%$ very rare) with an average of 2.51 at a standard deviation of .211 compared to men who are jealous of other people rarely and very rarely 32 subjects $-34.41 \%(12.90 \%$ rarely and $21.51 \%$ very rare) with an average of 2,51 to a standard deviation of .211. Women are more likely to cry more than men: 8 subjects $-8,60 \%$ $(8,60 \%$ of them) with an average of 2,73 at a standard deviation of .990 compared to men who often complain often and very often: 6 subjects $5.45 \%$ (4.30\% often, $\%$ very often) with an average of 1.98 at a standard deviation of 1.087 . The proportion in which men complain very rarely and rarely is very high, namely 24.73 very rarely and $20.43 \%$ rarely. Women are more dissatisfied with their lives than men. Women claim to be satisfied with their lives, 7 subjects $-7.53 \%$ (5.38\% often, $2.15 \%$ very often) with an average of 2.70 at a standard deviation of 1,127 compared to men who are satisfied of their lives often and very often, 18 subjects - 19.36\% (13.98\% often and $5.38 \%$ very often) with an average of 3.13 at a standard deviation of 1.127. Women are unhappier with their lives than men. Women claim to be happy, only 7 subjects $-7.53 \%$ (5.38\% often and $2.15 \%$ very often) with an average of 2.76 at a standard deviation of 1,065 compared to men who are often happy very often: 24 subjects - 25.81\% (25.81\% often and $0 \%$ very often) with an average of 3.21 at a standard deviation of .825. All women feel more unfulfilled than men. Of these, only 7 subjects $-7.53 \%(3.23 \%$ often, or $4.30 \%$ very often) with an average of 2.86 at a standard deviation of 1,084 vs. men, of which often and very often 19 subjects $-20.43 \%(18.28 \%$ often, $2.15 \%$ very often) with an average of 3.08 at a standard deviation of .900 .

Tabel no. 1. Values of attitude towards self and towards life of people with physical disabilities

\begin{tabular}{|l|c|c|c|c|c|c|c|}
\hline Frequency/ & $\begin{array}{c}\text { very } \\
\text { rarely }\end{array}$ & $\begin{array}{c}\text { quite } \\
\text { rarely }\end{array}$ & sometimes & often & $\begin{array}{c}\text { very } \\
\text { often }\end{array}$ & mean & $\begin{array}{c}\text { standard } \\
\text { deviation }\end{array}$ \\
\hline
\end{tabular}


Journal Plus Education, ISSN: 1842-077X, E-ISSN (online) 2068-1151 Vol XIX (2018), No. 1. pp. 131-143

\begin{tabular}{l} 
Am I going to get angry when I fail to do what I propose. \\
\hline
\end{tabular}

I was surprised to have feelings of jealousy towards people who do not experience the same deficiency.

\begin{tabular}{|l|l|c|c|c|c|c|c|c|}
\hline & Men & $21.51 \%$ & $12.90 \%$ & $12.90 \%$ & $10.75 \%$ & $2.15 \%$ & 2.32 & .165 \\
\hline & Women & $13.98 \%$ & $2.15 \%$ & $6.60 \%$ & $6.45 \%$ & $2.15 \%$ & 2.51 & .211 \\
\hline
\end{tabular}

I'm going to cry without reason.

\begin{tabular}{|l|l|c|c|c|c|c|c|c|}
\hline & Men & $24.73 \%$ & $20.43 \%$ & $6.60 \%$ & $4.30 \%$ & $2.15 \%$ & 1.98 & 1.087 \\
\hline \multirow{2}{*}{ women } & $6.45 \%$ & $6.45 \%$ & $18.28 \%$ & $8.60 \%$ & $0 \%$ & 2.73 & .990 \\
\hline
\end{tabular}

I'm a person happy with my life.

\begin{tabular}{|l|l|c|c|c|c|c|c|c|}
\hline & Men & $2.15 \%$ & $12.90 \%$ & $25.81 \%$ & $13.98 \%$ & $5.38 \%$ & 3.13 & .974 \\
\hline & women & $8.60 \%$ & $4.30 \%$ & $19.35 \%$ & $5.38 \%$ & $2.15 \%$ & 2.70 & 1.127 \\
\hline
\end{tabular}

I'm happy.

\begin{tabular}{|l|l|c|c|c|c|c|c|c|}
\hline & Men & $2.15 \%$ & $8.60 \%$ & $23.66 \%$ & $25.81 \%$ & $0 \%$ & 3.21 & .825 \\
\hline & women & $6.45 \%$ & $6.45 \%$ & $19.35 \%$ & $5.38 \%$ & $2.15 \%$ & 2.76 & 1.065 \\
\hline
\end{tabular}

I think I'm a happy person with my life at the moment.

\begin{tabular}{|l|l|l|l|l|l|l|l|c|}
\hline & Men & $2.15 \%$ & $12.90 \%$ & $24.73 \%$ & $18.28 \%$ & $2.15 \%$ & 3.08 & .900 \\
\hline & women & $4.30 \%$ & $8.60 \%$ & $19.35 \%$ & $3.23 \%$ & $4.30 \%$ & 2.86 & 1.084 \\
\hline
\end{tabular}

The items that men record higher values are: Do I get angry when I fail to do what I propose and Others are to blame for what happens to me. For the item Do I get angry when I can not do what I propose, men show good results: 27 subjects - 29.03\% (26.88\% often, $2.15 \%$ very often) with an average of 3.38 at a standard deviation of .882 compared to women who are 
often annoyed and very often only 14 subjects - $14.05 \%(12.90 \%$ often and $2.15 \%$ very often) with an average of 3.05 at a standard deviation of 1.129 . Men consider that are to blame for what happens to them in a higher proportion than women: 8 subjects $-8.60 \%(2.15 \%$ often and $6.45 \%$ very often) with an average of 2, 14 at a standard deviation of .177 compared to women who consider to be often responsible and very often only 2 subjects $2.15 \%$ often with an average of 1.78 at a standard deviation of .160 . We have found the following positive Sperman Correlations with average values: I was surprised to feel jealous of people who do not face the same deficiency / I happen to complain without reason $-(\rho=.546, \mathrm{p}<0.01)$; I am a person happy with my life / I am happy $(\rho=.653, p<0.01)$; I am happy / I think I am a person thanks to my life at the moment - $(\rho=.662, p<0.01)$; respectively, positive correlation, high value: I am a person thanks to my life / I think I am a satisfied person of my life at the moment - .721 (p-0.01). The results of the one-way ANOVA test confirm the above: $\mathrm{F}=11,300, \mathrm{p}<.001$ between crying without reason and gender respectively $\mathrm{F}=5.425, \mathrm{p}<.022$ between being happy and gender and also $\mathrm{F}=3,695, \mathrm{p}<.058$ between being satisfied with life and gender. Calculation of the Chi Square test brings significant differences by gender and Mi happens to cry without reason for a $\chi^{2}$ (4) = $20,263, p=0,000$ with a moderate effect for a Phi $\varphi=0,467$. Significant values for the Chi Square test have been recorded: by gender and I am a person satisfied with my life for a $\chi^{2}(4)=9,827, p=0,043$; by gender and for a $\chi^{2}(4)=13,829, p=0,008$ as well as by gender and I am a person fulfilled for a $\chi^{2}(4)=9,039, p=0,060$. The second hypothesis of the research was: we anticipate that self-valoing of motor deficiencies depends on the nature of the deficiency (inborn or acquired) and the level of education (gymnasium, lyceum, university) of the person with motor deficiencies (people with inborn deficiency with higher studies is better value for yourself). Self-evaluation was investigated through ten items of the questionnaire for which a median Alpha Chronbach Coefficient (0.888) was calculated: I wish I was born the second time; I think I'm a valued man or at least as good as the others; I think I have some remarkable qualities; I incline to think that I am a lost or unfulfilled man; I do not think I have too many things to boast; I have a positive attitude towards my own person; Overall I'm happy with myself; I wish I could have more respect for my own person; From time to time I feel like I'm useless; Sometimes I think I'm not good for anything. People with motor disabilities investigated generally can say that they do not have a low self-worth. Only three of the ten investigated items achieved lower averages: I wish I was born the second time (average - 2.85 for a standard deviation of: 1,343); I wish I could have more respect for my own (average - 2,60 for a standard deviation of 1,208); From time to time I feel that I'm useless (average -2.87 for a standard deviation of: 1,270). These 
items refer to what those people want or how they feel sometimes. For most items, high average values are recorded as follows: I think I'm a value man or at least as good as the others (average - 3.39 for a standard deviation of: 1,152); I think I have some remarkable qualities (average - 3.22 for a standard deviation of: 1,121); I have a positive attitude towards my own (average - 3.37 for a standard deviation of: 1.284); Overall, I am satisfied (average - 3.29 for a standard deviation of: 1,230). For the items with negative forms, there were recorded values that strengthened the idea of selfvalorisation: I tend to think that I am a missed or unrealized person $(61,30 \%$ disagreed subjects, of which $31,2 \%$ - partial disagreement and $30.1 \%$ - total disagreement); I do not think I have much to boast (48.4\% disagreements, of which 33.3\% - partial disagreement and 15.1\% - total disagreement, plus $28 \%$ expresses somewhat); Sometimes I think I'm not good at anything (51.6\% disagreements, of which $20.4 \%$ - partial disagreement and $31.2 \%$ total disagreement, plus $17.2 \%$, which expressed somehow).

We have found the following positive correlations with a mean value: I think I am a valued person or at least as good as others / I think I have some remarkable qualities $(\rho=.679, p<0.01)$; I think I am a valued person or at least as good as others / I have a positive attitude towards my own person $(\rho=.619, p<0.01)$; I think I am a valued man or at least as good as the others / Overall I am pleased $(\rho=.608, p<0.01)$; I think I'm a valued person or at least as good as others/ I wish I could have more respect for my own person $(\rho=.613, p<0.01)$; I think I have some remarkable qualities / I have a positive attitude towards my own person $(\rho=.586, p<0.01)$; I think I have some remarkable qualities / Overall I am pleased $(\rho=.633, p<0.01)$; From time to time I feel like I'm useless / Sometimes I think I'm not good for anything $(\rho=.791, p<0.01)$; respectively, positive correlation with high value: I have a positive attitude towards my own person / Overall I am pleased $(\rho=.783$, $\mathrm{p}<0.01$ ); If we look at comparative self-valuing, depending on the nature of the deficiency: innate or acquired, we will see a net distribution of the results in favor of the innate deficiency. People with inborn deficiency are better off than those with a deficiency. We will present the average values and the standard deviation for the items in the questionnaire. So for the item: I wish I was born the second time - an average value of 2.90 was obtained at a standard deviation of 1,324 for congenital deficiencies compared to an average of 2,63 at a standard deviation of 1,455 for those who have acquired the deficiency. Under item: I think I am a valued man or at least as good as the others - an average value of 3.56 was obtained at a standard deviation of .909 for congenital deficiencies compared to an average of 2.50 at Standard deviation of 1,713 for those who have deficient. For I think I have some remarkable qualities - an average value of 3.39 was obtained at a standard deviation of .934 for inborn deficiencies compared to an average of 2.38 at a 
standard deviation of 1.544 for those who have acquired deficiency. Item results: I tend to think I am a missed or unrealized person - a 3.92 average value was obtained at a standard deviation of 1,010 for congenital deficiencies compared to an average of 2.38 at a standard deviation of 1.544 for those who have acquired the deficiency. Under item: I do not think I have much to praise - a 3.45 average value was obtained at a standard deviation of 1,020 for congenital deficiencies compared to an average of 2.71 at a standard deviation of 1,637 for those who have acquired the deficiency. I have a positive attitude towards my own - an average of 3.57 was obtained at a standard deviation of 1,129 for congenital deficiencies compared to an average of 2.38 at a standard deviation of 1,544 for those who have acquired the deficiency. For the issue: Overall, I am satisfied - an average value of 3.48 was obtained at a standard deviation of 1.071 for birth defects compared to an average of 2.38 at a standard deviation of 1.544 for those who have acquired deficiency. Under item: I wish I could have more respect for my own - a 2.68 average value was obtained at a standard deviation of 1.057 for congenital deficiencies compared to an average of 2.25 at a standard deviation of 1,770 for those who have acquired the deficiency. For: From time to time I feel unnecessary - an average value of 3.05 was obtained at a standard deviation of 1,180 for congenital deficiencies compared to an average of 2.00 at a standard deviation of 1,366 for those who have acquired the deficiency. Finally, for the item: Sometimes I think I'm not good at anything - a 3.66 average value was obtained at a standard deviation of 1,284 for birth defects compared to an average of 1.88 at a standard deviation of 1.408 for those who have acquired the deficiency.

Calculation of Chi square values brings significant differences after $I$ think that I am a wobbler or at least as good as the others and the nature of the deficiency (innate or acquired) for a $\chi^{2}(4)=21,721, p=0,000$ with a moderate effect a Phi $\varphi=0.483$. Significant values for the Chi Square test have been recorded: by the nature of the deficiency (innate or acquired) and $I$ think I have some remarkable qualities for a $\chi^{2}(4)=16,521, p=0,002$ with a moderate effect for a Phi $\varphi=0,421$; by the nature of the deficiency (innate or acquired) and I do not think I have many things to praise for an $\chi^{2}$ (4) = $20.148, p=0.000$ with a moderate effect for a coefficient Phi $\varphi=0.471$; as well as the nature of the deficiency (innate or acquired) and Overall, I am pleased overall with a $\chi^{2}(4)=17,029, p=0,002$ with a moderate effect for a Phi $\varphi=0,428.5$. 
Journal Plus Education, ISSN: 1842-077X, E-ISSN (online) 2068-1151 Vol XIX (2018), No. 1. pp. 131-143

\section{Conclusions}

Women more than men feel that the presence of disability affects their attitude towards themselves and to life. Women are the ones who develop jealousy toward those who do not face the same difficulty - an average of 2.51 at a standard deviation of .211 compared to men who are jealous of other people - with an average of 2.51 per deviation standard .211. Women are the ones who complain without reason more than men - an average of 2.73 at a standard deviation of .990 against men who complain without reason - an average of 1.98 at a standard deviation of 1.087. Women are more dissatisfied with their lives than men - an average of 2.70 at a standard deviation of 1,127 compared to men who are satisfied with their lives with an average of 3.13 at a standard deviation of 1,127. Women are unhappier with their lives than men - an average of 2.76 at a standard deviation of 1,065 compared to men who are happy - with an average of 3.21 at a standard deviation of .825. All participating women are more unfulfilled than men. - an average of 2.86 at a standard deviation of 1,084 vs. men with an average of 3.08 at a standard deviation of .900 . Self-valuing by comparison, depending on the nature of the deficiency: innate or acquired, presents a distribution of results in favor of the innate deficiency. Motorized deficiencies that have been born with motor incapacity are better off than those who have acquired shortages throughout their lives. Thus, inherited motor deficiencies consider themselves to be valuable or at least as good as others - an average value of 3.56 at a standard deviation of .909 compared to an average of 2.50 at a standard deviation of 1,713 for those who have acquired the deficiency. Inborn motoric deficiencies are believed to have some remarkable qualities - the average of 3.39 at a standard deviation of .934 compared to an average of 2.38 at a standard deviation of 1.544 for those who have acquired the deficiency. Positive attitude towards one's own have all those with inborn deficiency - the average of 3.57 at a standard deviation of 1,129 compared to an average of 2.38 at a standard deviation of 1,544 compared to those who have acquired the deficiency. Thanks to them are all those with inborn deficiency - the average of 3.48 at a standard deviation of 1,071 vs. an average of 2.38 at a standard deviation of 1,544 for those who have acquired the deficiency. 
Journal Plus Education, ISSN: 1842-077X, E-ISSN (online) 2068-1151 Vol XIX (2018), No. 1. pp. 131-143

\section{References}

Bult, M.K.; Verschuren, O.; Jongmans, M.J.; Lindeman, E.; Ketelaar, M. (2011). What influences participation in leisure activities of children and youth with physical disabilities? A systematic review. Research in Developmental Disabilities Volume 32, (5), 1521-1529

Van Campen, C.; Cardol, M. (2009). When work and satisfaction with life do not go hand in hand: Health barriers and personal resources in the participation of people with chronic physical disabilities Social Science \& Medicine, 69, (1), 56-60.

Dvir, N. (2015). Does physical disability affect the construction of professional identity? Narratives of student teachers with physical disabilities Teaching and Teacher Education, 52, 56-65.

Gaskin, C.. J.; Andersen, M. B.; Morris, T. (2010). Sport and physical activity in the life of a man with cerebral palsy: Compensation for disability with psychosocial benefits and costs. Psychology of Sport and Exercise, 11 (3), 197-205.

Lovelock, B.A. (2010). Planes, trains and wheelchairs in the bush: Attitudes of people with mobility-disabilities to enhanced motorised access in remote natural settings. Tourism Management, Volume 31 (3), 357-366.

Law, M.; Petrenchik, T.; King, G.; Hurley, P. (2007). Perceived Environmental Barriers to Recreational, Community, and School Participation for Children and Youth With Physical Disabilities. Archives of Physical Medicine and Rehabilitation, 88, (12), 1636-1164.

Martin, J. J.; Choi, Y. S. (2009). Parents' physical activity-related perceptions of their children with disabilities. Disability. and Health Journal, Volume 2 (1), 9-14.

McDermott, S.; Turk, M.A. (2011). The myth and reality of disability prevalence: measuring disability for research and service. Disability and Health Journal, 4(1), 1-5.

Nkabinde, Z. P.; Obiakor, F.E., Offor, M.T.; Smith, D.J. (2010). Educating Children with Physical Disabilities. International Encyclopedia of Education (Third Edition), 640-645.

Ogilvie, R.; Foster, K.; McCloughen, A.; Curtis, K. (2015). Family members' experience of providing support for young people with traumatic physical injury during the acute hospital phase of care: A qualitative study. Injury, 46, (9), 1834-1840.

Schreuer, N.; Sachs, D.; Rosenblum, S. (2014). Participation in leisure activities: Differences between children with and without physical disabilities. Research in Developmental Disabilities, Volume 35, (1), 223233. 
Stănescu, R. (2014). Wheelchair Tennis - An Opportunity for Social Integration of the People with Disabilities Original Research Article Procedia - Social and Behavioral Sciences, Volume 149 (5), 906-910.

Stevens, S. E.: Steele, C. A.; Jutai, J. W.; Kalnins, I. V.; Bortolussi, J. A.; Biggar, W. D. (1996). Adolescents with physical disabilities> Some psychosocial aspects of health. Journal of Adolescent Health, Volume 19, (2), 157-164.

Stewart, M.; Barnfather, A.; Magill-Evans, J.; Ray, L.; Letourneau, N. (2011).Brief report: An online support intervention: Perceptions of adolescents with physical disabilities. Journal of Adolescence, Volume 34, (4), 795-800.

Tate, D. G; Riley, B. B.; Perna, R.; Roller, S. (1997). Quality of life issues among women with physical disabilities or breast cancer. Archives of Physical Medicine and Rehabilitation, 78, (12-5), S18-S25.

Trani, J.-F.; Ballard, E.; Peña, J. B. (2016). Stigma of persons with disabilities in Afghanistan: Examining the pathways from stereotyping to mental distress. Social Science \& Medicine, 153, 258-265.

White, G. W.; Gonda, C.; Peterson, J. J.; Drum, C. E. (2011). Secondary analysis of a scoping review of health promotion interventions for persons with disabiities: Do health promotion interventions for people with mobility impairments address secondary condition reduction and increased community participation? Disability and Health Journal, 4 (2), 129-139.

Wilson, P. G.; Reid, D. H.; Green, C. W. (2006). Evaluating and increasing in-home leisure activity among adults with severe disabilities supported independent living. Research in Developmental Disabilities, Volume 27, (1), 93-107.

Yalon-Chamovitz, S.; Weiss (Tamar) P. L. (2008). Virtual reality as a leisure activity for young adults with physical and intellectual disabilities. Research in Developmental Disabilities, 29, (3), 273-287. 